\title{
ASPECTS OF BIODETERIORATION OF LAPIDEOUS SUBMERGED ARTEFACTS: 3D METHODOLOGIES APPLICATION
}

\author{
S. Ricci ${ }^{\mathrm{a}}$, F. Antonelli ${ }^{\mathrm{b}}$, C. Sacco Perasso ${ }^{\mathrm{b}}$ \\ ${ }^{a}$ Istituto Superiore per la Conservazione ed il Restauro, Via di San Michele 23 Rome - sandra.ricci@beniculturali.it \\ ${ }^{\mathrm{b}}$ Istituto Superiore per la Conservazione ed il Restauro, Via di San Michele 23 Rome, research collaborator \\ fedantonelli@gmail.com; carlotta.sacco@ hotmail.it
}

Commission V

KEY WORDS: Biodeterioration, Archaeological artefacts, 3D techniques, Bioerosion, Baiae

\begin{abstract}
:
Submerged stone archaeological artefacts are bioeroded by endolithic microbiota (cyanobacteria, algae and fungi) and macroborers (Porifera, Bivalvia and Sipuncula). Optical microscope and SEM observations permit to analyse the bioerosion traces and to identify bioeroders. Data obtained with these techniques cannot be used to estimate volumes of material bioeroded. This aspect require the need to collect three-dimensional, close-range data from artefact. In this work we illustrate two 3D imaging techniques used to study bioerosion phenomena of underwater Cultural Heritage. In particular Digital Video Microscope permit the elaboration of 3D images, which are widely employed for close-range acquisitions. Underwater Laser Scanner documents the in situ degradation of submerged artefacts. This research aims to sensitize specialist figures in the study 3D offering a starting point for future collaborations that could lead to interesting results.
\end{abstract}

\section{INTRODUCTION}

The submerged stone artefacts are subjected to bioerosion caused by marine micro- and macroorganisms. In this paper we report some results of biological studies carried out on lapideous submerged artefacts from the Underwater Archaeological Park of Baiae (Naples).

Today the remains of the city of the Roman Age, lie underwater at a distance of up to $400-500 \mathrm{~m}$ from the coast at a depth of 5-7 m. The interaction between natural processes and human activity has produced a marine environment characterized by a huge variety of natural habitats. For this reason in 2002 an Underwater Park, Marine Protected Area (MPA) was created covering around 176.6 hectares. The submerged area includes part of the territory of the ancient city of Baiae and Portus Iulius, comprising the Roman harbour and numerous constructions used as warehouses.

The biodeterioration study is part of the CoMAS Project (Conservation programmed in situ of Underwater Archaeological Heritage, http://www.comasproject.eu) headed by UNICAL, with ISCR as consultant, and in collaboration with the Special Superintendence for the Archaeological Properties of Naples and Pompeii. Studies conducted until today have examined artefacts still in situ (mosaic floors made of opus sectile and wall structures) and artefacts recovered from the seabed (fragments of statues and marble slabs). The results have shown the dangerous biological activity explicated by different groups of endolithic biodeteriogens able to perforate the stone (Ricci et al., 2007; Ricci et al., 2008a, 2008b; Davidde et al., 2010; Ricci and Davidde, 2012; Ricci et al., 2013; Ricci et al., 2014).

The aim of this paper is to illustrate problems related to bioerosion phenomena of submerged archaeological artefacts and to present some potential application of $3 \mathrm{D}$ visualization techniques in this field of study.

\section{BIODETERIORATION: BIOEROSION}

The first step of the colonization of a submerged artefact is the biofilm formation; at a later stage a mixed population sets up whose components are different basing on the expositive conditions (biofouling). It has been experimentally demonstrated that, after few months, exposed surfaces are covered by plants and animals, most of them produce carbonatic or organic encrustations: Rhodophyta Corallinaceae, Foraminifera, Porifera, Anellida, Arthropoda, Bryozoa, Brachiopoda (Casoli et al., 2014).These organisms form a layer that can reach considerable thickness (some $\mathrm{cm}$ ); this stratum modifies the original morphology of the artefact but it assumes a protective function against erosion. Furthermore it reduces endolithic colonization avoiding the settlement of boring organisms.

In marine environments macroborers are the most damaging; they include lithophagine bivalves, clionaid sponges and sipunculans and are capable of excavating cavities and tunnels of various dimensions. Boring bivalves belong to different species: Lithophaga lithophaga Linnaeus, Petricola lithophaga Retzius, Rocellaria dubia Pennant. These bivalves play an essential role in the deterioration of archaeological remains because they produce boreholes of great dimensions (up to $2 \mathrm{~cm}$ in diameter) (Fig. $1 \mathrm{D}, \mathrm{E}$ ) that lead to the total destruction of the artefact. Rocellaria dubia is a fastgrowing species and its tunnels can reach $1 \mathrm{~cm}$ of length in two years (Ricci et al., 2014).

The erosion activity of sponges can be very extensive and severe; the extension and diffusion of the cavities can reach about $80 \%$ of the volume of the substratum. The stone material is so extensively bored that only thin layers of rock, surrounding the cavity excavated by the sponges, remains. These organisms produce sub-spheroidal cavities, linked by tunnels. The sponge attack is evident to the naked-eye for the presence of circular holes (with diameters of several millimetres) on the surface of the artefact (Fig. 1 A). Sponge identification is primarily based on the SEM observation of skeletal elements (spicules) and of patterns of bioerosion in the samples (Fig. 1 B, C). The most frequent species, 
belonging to the Family Clionaidae, are: Cliona celata Grant, Cliona viridis Schmidt, Cliona janitrix Topsent, and Dotona cf. pulchella mediterranea Uriz \& Rosell (Ricci et al., 2008b; Sacco Perasso et al., 2015). Beside these endolithic taxa, insinuating sponges have been identified; they do not bore the substratum but only occupy cavities previously excavated by boring sponges.

Sipunculans (Protostomia) unsegmented, vermiform, coelomate marine benthic animals, cause a serious loss of material that can lead to the complete destruction of the stone in areas already colonized by clionaid sponges. The species Aspidosiphon muelleri Diesing was found on submerged Cultural Heritage (Fig. 1 F) (Antonelli et al., 2015).

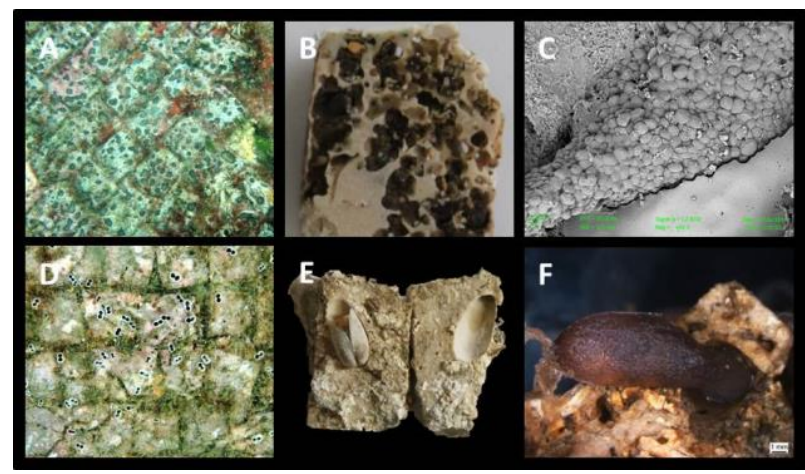

Fig. 1. A - Mosaic floor colonized by boring sponges; B Section of a mosaic tessera bioeroded by boring sponges; $\mathrm{C}$ SEM microphotograph of a resin cast clionaids sponge; $\mathrm{D}$ - Mosaic colonized by the bivalve Rocellaria dubia; E -

Mosaic tesserae with specimen of Rocellaria dubia inside its burrow; F - The boring sipunculans Aspidosiphon muelleri.

Microboring is produced by phototrophic and chemotrophic microorganisms which actively penetrate inside hard substrates by biochemical dissolution. Microborers include cyanobacteria, algae and fungi. Light plays an important role and it is a critical factor in the depth distribution of phototrophic endolithic microorganisms (Fig. 2 A), whereas fungi are light-independent and depend on organic sources. The traces left by these microorganisms are visible inside the lapideous material through optical and SEM observations of polished sections (Fig. $2 \mathrm{~B}, \mathrm{C}$ ); in this way data on the extent of the attack and depth of penetration are obtained. These analyses also give information on the diameters of the perforations but do not allow the identification of the microorganism producing the traces; this is achieved by the embedding-casting resin technique: perforations are filled with a resin forming casts of the tunnels that are freed from the lapideous material by acid dissolution (Golubic et al., 1970; Ricci et al., 2013). The casts (called ichnotaxa) are perfect replicas of the microorganisms because the tunnels burrowed reproduce the morphology of the borer (Fig. 2 D). Previous studies provided the identification of some microboring species and the definition of their ecological features. The microbioerosion is dominated by Chlorophytes (ichnospecies Ichnoreticulina elegans Radtke - biospecies Ostreobium quekettii Bornet \& Flahault; Rhopalia clavigera Golubic - biospecies Eugomontia sacculata Kornmann; Rhopalia catenata Radtke - biospecies Phaeophila dendroides Batters). Cyanobacteria are present with the ichnospecies Eurygonum nodosum Schmidt - biospecies Mastigocoleus testarum Lagerheim, Fascichnus dactylus Radtke - biospecies Hyella caespitosa Bornet and Flahault,
Scolecia filosa Radtke - biospecies Plectonema terebrans, Bornet and Flahault. Traces belonging to microfungi are Orthogonum fusiferum Radtke - biospecies Ostracoblabe implexa Bornet \& Flahault, Saccomorpha clava Radtke biospecies Dodgella priscus Zebrowski and Saccomorpha sphaerula Radtke - biospecies Lithopytium gangliforme Bornet \& Flahault (Golubic et al., 1970; Le CampionAlsumard, 1979; Golubic et al., 1981)

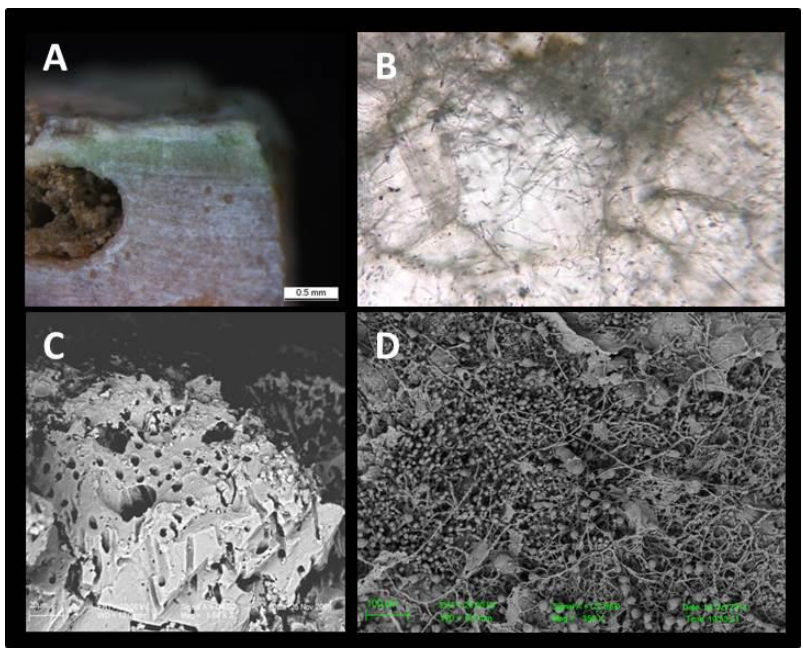

Fig. 2. A - Section of a mosaic tessera with an evident colonization caused by microflorabiota (green layer); B Microboring burrows inside marble crystals (transmitted light microscopy); C - SEM microphotograph of microborings; D - microphotograph of endolithic microflorabiota cast (SEM).

The knowledge of the damage level, although studied on recovered artefacts, defines the degree of hazard posed by the immersion conditions and to establish the necessary interventions for preserving the artefacts in the future. The studies highlighted that artefacts such as statues and architectural structures cannot remain in water if free from sediment because bioerosion processes lead inevitably to their destruction. In these circumstances, the recovery of finds is necessary; if recovering is not possible it is required to define the state of preservation to develop conservation procedures to prevent or stop biodeterioration phenomena.

\section{3D METHODOLOGIES APPLICATION}

Optical microscope and SEM observations permit the identification of biodeteriogens responsible for the biodegradation. Despite this, data obtained cannot be used to estimate volumes of material bioeroded. Digital Video Microscope (Leica DVM 2500) has been used for this detailed purpose. This instrument offers the advantage of performing a large variety of qualitative and quantitative analysis without requiring sample preparation. One of the main features of the DVM is to create models of the surface structures observing micro and / or macroscopic samples; for this reason its use is particularly useful for the study of the surfaces of a degraded artefact.

Marble slabs made of opus sectile collected from the seabed of the Underwater park of Baiae were examined (Davidde Petriaggi et al., 2014b). The observations conducted provided multifocal images of a portion of the surface of the sample bioeroded by endolithic sponges belonging to the family Clionaidae. 

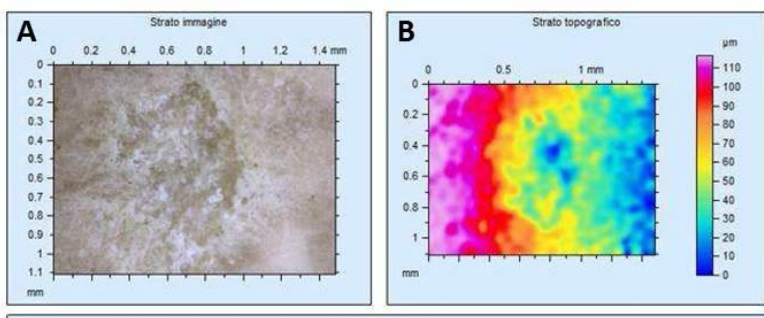

C

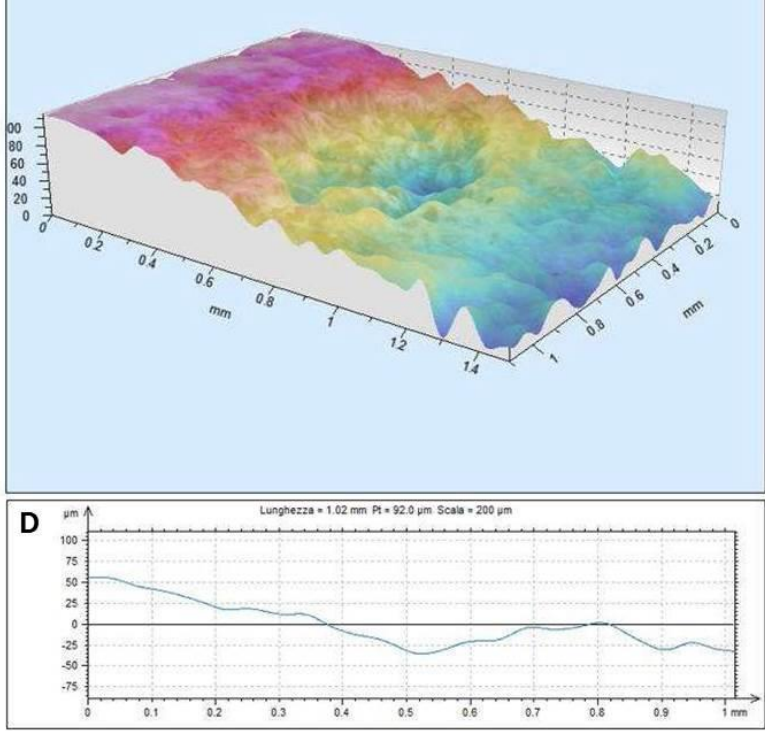

Figure 3. A - DVM multifocal image; B - DVM topographic map; C - 3D topographic rendering; D - Profile of a virtual section of the sample.

From scanned images and associated metadata has been possible to obtain a topographic map, in false colour (Fig. 3 B), which allowed us to evaluate the roughness of the surface and then to quantify the areas and volumes bioeroded by biodeteriogens.

The images obtained with the DVM and the measurement data related to them allow us - through the elaboration of LAS Map software - to obtain graphics and 3D models (Fig. $3 \mathrm{C}$ ) from which it is possible to extrapolate measurements of distance, surface morphology and volume.

With this instrument it is also possible to perform the extraction of profiles of virtual sections of the sample (Fig . 3 D), by selecting different transects and making comparisons between them. In the 3D image all the acquired data are displayed in a topographic restitution. These data, when combined with the SEM morphological observations, allow an accurate and precise definition of the superficial modifications detected. Since often the manifestation on the surface of the biological colonization caused by macroborers does not reflect the extent of this degradation in the material (because external holes are often much smaller than the burrows eroded by the organisms), destructive techniques are necessary to investigate the state of preservation of the inner part of the material.

The use of techniques requiring the cutting of the artefacts in different parallel sections (Fig. 4A) allows to get quantitative data regarding bioerosive activity calculated by means of image analysis (using the image analysis software Image J) and calculation of eroded surfaces. These data do not allow to obtain a three-dimensional reconstruction of the degradation. The usefulness of the silicone-cast technique is evident, because it allows to obtain a complete filling of the cavities present inside the artefact. Good results were obtained with infiltration of silicone Silical 120 (CTS) into the burrows excavated by boring animals, such as sponges and bivalves. Tests carried out on limestone tiles highly degraded by clionaid sponges permitted to obtain complete casts of the portions of the bioeroded tesserae that faithfully reproduce the morphological and spatial arrangement of the internal burrows (Fig. 4 B,C).

The casts can be morphologically interpreted obtaining a precise localization of the burrows inside the studied sample; they can be used for graphic processing that lead to the elaboration of three-dimensional images and can be an interesting study material for 3D reconstructions.

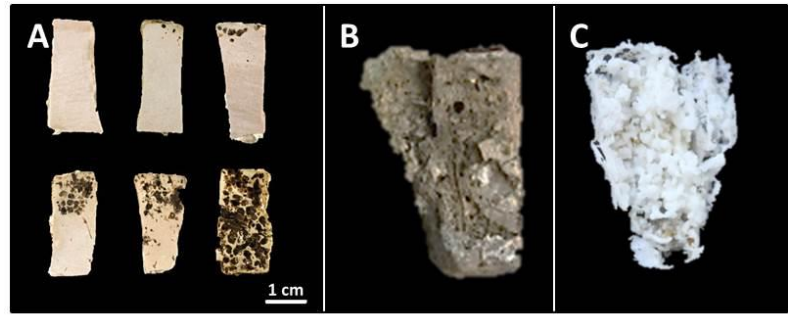

Figure 4. A - Increasing bioerosion levels observed in sections of mosaic tesserae; B - Tessera with sponge pitting; $\mathrm{C}$ - Silicon cast of the bioerosion pattern of the tessera in Fig. 4B.

In the field of underwater archaeology and marine biology for the study of Underwater Cultural Heritage are often necessary non-destructive techniques to study ancient artefacts that cannot be moved from their site.

It is particularly helpful to use the Underwater laser Scanner, a short-range measurement system that is ideal for capturing high-detail measurements (within millimetres).

With this instrument it is possible to get data and process accurate images providing a point definition of the state of conservation. An important application is to monitor over time the state of preservation of submerged artefacts, such as walls and opus sectile mosaic floors. In the field of marine biology, the laser scanner is useful to define the colonization dynamics of the surfaces exposed to marine environment (and consequently to biodeteriogens) and to study the type and extent of degradation (Davidde Petriaggi et al., 2014a).

This technique has been specifically used to document a peculiar differential degradation detected on a bichrome mosaic floor currently submerged in the Underwater Archaeological Park of Baiae at a depth of about $5 \mathrm{~m}$ (Fig. 5). The pavement made of calcareous white tesserae and dark tesserae consisting of leucitite showed an evident lowering of the exposed lapideous layer in conjunction with the rows made of dark tiles (Azzaro et al., 1976). White tesserae showed traces of bioerosion caused by endolithic forms that were manifested as small circular perforations visible on the surface (pitting). The state of conservation has been well documented by laser scanner. The processed images provide an accurate three-dimensional reconstruction of a portion of the mosaic characterized by this type of degradation with a sub-millimetric precision (photo archive ISCR). The scans were carried out using a laser scanner Naumacos L3, (info@naumacos.com). 


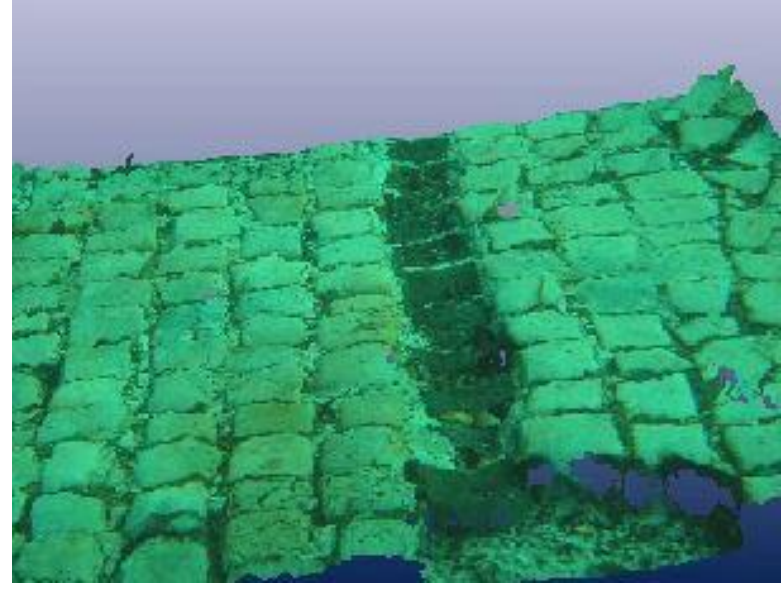

Figure 5. Underwater laser Scanner digital model of a part of a mosaic floor.

\section{CONCLUSIONS}

The data obtained represent a first phase of documentation and processing that has allowed us to define the great utility of these surveys, setting the stage for further development and applications. Finally, the research aims to sensitize specialist figures in the study $3 \mathrm{D}$ offering a starting point for future collaborations that could lead to interesting results.

\section{REFERENCES}

Azzaro E., Barrese E., Di Sabatino B., Giampaolo C., 1976. Processi secondari su leuciti: l'halloysitizzazione in prodotti lavici a sud-ovest del Lago di Bracciano. Confronto con risultati sperimentali. Rendiconti Società Italiana Mineralogia e Petrologia, 32, pp. 647-659.

Antonelli, F., Sacco Perasso, C., Ricci, S., Davidde Petriaggi, B., 2015. First report of the boring Sipuncula Aspidosiphon muelleri Diesing 1851 on underwater Cultural Heritage. International Biodeterioration and Biodegradation 100, pp. 133-139.

Casoli, E., Ricci, S., Gravina, M.F., Belluscio, A., Ardizzone, G., 2014. Settlement and colonization of epi-endobenthic communities on calcareous substrata in an underwater archaeological site. Marine Ecology: an Evolutionary Perspective, pp. 1-15.

Davidde, B., Ricci, S., Poggi, D., Bartolini, M., 2010. Marine bioerosion of stone artefacts preserved in the Museo archeologico dei campi Flegrei in the Castle of Baia (Naples). Archaeologia Maritima Mediterranea 7, pp. 75-115.

Davidde Petriaggi, B., Petriaggi, R., Gomez de Ayala, G., 2014a. 3D documentation for the assessment of Underwater Archaeological remains. Archaeology in the Digital Era, Volume II, Amsterdam University press, pp. 174-180.

Davidde Petriaggi B., Ricci S., Priori G. F., La Russa M., Ruffolo S. A., 2014b. Use of the digital video microscope (DVM) for non-destructive studies in the field of the conservation of stone materials. Art'14 - 11th International Conference on Non-Destructive Investigations and
Microanalysis for the Diagnostics and Conservation of Cultural and Environmental Heritage.

Golubic, S., Brent, G., Le Campion-Alsumard, T., 1970. Scanning electron microscopy of endolithic algae and fungi using a multipurpose casting-embedding technique. Lethaia 3, pp. 203-209.

Golubic, S., Friedmann, I., Schneider, J., 1981. The lithobiontic ecological niche, with special reference to microorganisms. Sedimentary Geology 51, pp. 475-478.

Le Campion-Alsumard, T., 1979. Les cyanophycées endolithes marines. Systématique, ultrastructure, écologie et biodestruction. Oceanologica Acta 2, pp. 143-156.

Ricci, S., Priori, G.F., Bartolini, M., 2007. Il degrado biologico dei manufatti archeologici dell'Area Marina Protetta di Baia. Bollettino ICR Nuova serie 14, pp. 116-126.

Ricci, S., Davidde, B., Bartolini, M., Priori, G.F., 2008a. Bioerosion of lapideous objects found in the underwater archaeological site of Baia (Naples). Archaeologia Maritima Mediterranea 6, pp. 167-188.

Ricci, S., Priori, G.F., Bartolini, M., 2008b. Bioerosione di pavimentazioni musive sommerse ad opera della spugna endolitica Cliona celata. Bollettino ICR Nuova serie 15, 7-18.

Ricci, S., Davidde, B., 2012. Some aspects of the bioerosion of stone artefact found underwater: significant casa studies. In: Williams, T., Gregory, D., Matthiensen, H., (Eds.), Conservation and management of archaeological sites, special issue: preserving archaeological remains in situ. Maney Publishing, 14 (1-4), pp. 28-34.

Ricci, S., Cadeddu, B., Melis, P., Manconi, R., 2012. The Azzurra Cave (Capri): first notes on fouling of Nymphaea. Biologia Marina Mediterranea 20 (1), 150-151.

Ricci, S., Pietrini, A.M., Bartolini, M., Sacco Perasso, C., 2013. Role of the microboring marine organisms in the deterioration of archaeological submerged lapideous artifacts (Baia, Naples, Italy). International Biodeterioration and Biodegradation 82, pp. 199-206.

Ricci, S., Sacco Perasso, C., Antonelli, F., Davidde Petriaggi, B., 2014. Marine bivalves colonizing roman artefacts recovered in the Gulf of Pozzuoli and in the Blue Grotto in Capri (Naples, Italy): boring and nestling species. International Biodeterioration and Biodegradation 98, pp. 89-100.

Sacco Perasso, C., Ricci, S., Davidde Petriaggi, B., Calcinai, B., 2015. Marine bioerosion of lapideous archaeological artifacts found in the Grotta Azzurra (Capri, Naples, Italy): Role of microbiota and boring Porifera. International Biodeterioration and Biodegradation, 99, pp. 146 - 156. 